\title{
Economic cognitive institutions
}

\author{
Enrico Petracca ${ }^{1 \star}$ and Shaun Gallagher ${ }^{2,3}$ \\ ${ }^{1}$ School of Economics, Management and Statistics, University of Bologna, Bologna, Italy, ${ }^{2}$ Department of Philosophy, \\ University of Memphis, Memphis, TN, USA and ${ }^{3}$ Faculty of Law, Humanities and Arts, University of Wollongong, \\ Wollongong, NSW, Australia \\ *Corresponding author. Email: enrico.petracca2@unibo.it
}

(Received 13 November 2019; revised 8 March 2020; accepted 9 March 2020; first published online 6 April 2020)

\begin{abstract}
This paper introduces the notion of 'cognitive' institution and discusses its relevance to institutional economics. Cognitive institutions are conceptually founded on the philosophy of mind notion of extended mind, broadened to also include the distinctly social, institutional, and normative dimensions. Cognitive institutions are defined as institutions that not just allow agents to perform certain cognitive processes in the social domain but, more importantly, without which some of the agents' cognitive processes would not exist or even be possible. The externalist point of view of the extended mind has already had some influence in institutional economics: Arthur Denzau and Douglass North first introduced the notion of institution understood in terms of 'shared mental models', and relatedly philosopher Andy Clark introduced the notion of 'scaffolding institution'. We discuss shared mental models and scaffolding institutions and go a step further by showing that the notion of cognitive institution can capture more fundamental and salient aspects of economic institutions. In particular, we focus on the market as an economic cognitive institution.
\end{abstract}

Keywords: Cognitive institution; market institutions; philosophical externalism; socially extended mind

\section{Introduction}

The conceptual distance between social scientists and philosophers regarding their approach to institutions has recently been remarked in the pages of this journal. Hindriks and Guala (2015: 460) claim that 'a scholar approaching the literature with a fresh mind may have the impression that philosophers and social scientists are talking about completely different things, when they talk about institutions.' Starting from this diagnosis, they advocate an 'increasing collaboration between philosophers and scientists interested in the ontology of the social world' (p. 478). A possible way to follow up this suggestion is to focus on social scientists' and philosophers' convergent interest in the study of the human mind. After decades of 'mindless' economics, the massive spread of behavioral economics has made social scientists and economists increasingly aware that 'adherence, knowing or unknowing, to a particular philosophy of mind can have profound effects on the ontology of the economy' (MarkeyTowler, 2016: 203). This awareness supports the idea advocated in this paper that taking philosophy of mind and its pluralism seriously may help to shed new light on the ontology of institutions in the social sciences and economics.

Although the potential of philosophy of mind for understanding economic institutions has so far been insufficiently explored, it would be a mistake to think that institutional economics and philosophy of mind have been separated fields. The importance of John Searle's notion of institution as 'constitutive rules' (Searle, 1995, 2010) for the development of institutional economics (Searle, 2005) can hardly be overestimated. It is, however, a different connecting thread between philosophy of mind and

(C) Millennium Economics Ltd 2020. This is an Open Access article, distributed under the terms of the Creative Commons AttributionNonCommercial licence (http://creativecommons.org/licenses/by-nc/4.0/), which permits unrestricted re-use, distribution, and reproduction in any medium, provided the original work is properly cited 
institutional economics that we see as particularly promising and worth following up. This thread originates in a collaboration over the conceptualization of economic institutions between institutional economist Douglass North and philosopher of mind Andy Clark. During the 1990s and early 2000s, North and Clark collaborated to establish the notion of economic institution on some form of what in philosophy of mind is called 'externalism' - that is, the view that does not restrict the ontology of mind to individuals' heads but emphasizes some constitutive (and therefore ontological) relationship between minds and environments. The cornerstone of this externalist agenda has been the 'extended mind' hypothesis introduced by Andy Clark himself with the collaboration of philosopher David Chalmers (Clark, 2008; Clark and Chalmers, 1998). We think that a convincing conceptualization of institutions crucially depends on taking the externalist position seriously and we regard this as a way to open up an entire program of research in institutional theory. ${ }^{1}$ As such, this research program would represent an alternative to more or less manifest internalist positions in institutional theory, among which Searle's is an eminent one. To see this, consider Searle's notion of methodological individualism intended as a way to sidestep (but ultimately to reject) externalism in institutional theory:

[An] issue that this definition of methodological individualism enables me to sidestep is that concerning 'externalism' in the philosophy of mind. I do in fact think that mental states are entirely in the head, but many contemporary philosophers think that the contents of mental states are not in the head but include, for example, causal relations to the real world and to the surrounding society. I do not think these views are true, but I do not need to refute them for the purpose of this investigation. I simply insist that all mental reality is in the minds of individuals. This is consistent with the theory that says mental contents and hence minds are not in heads, although I happen to think that theory is false (Searle, 2005: 21).

In contrast, in order to sidestep methodological individualism, and to further the externalist thread in institutional economics, we introduce the notion of 'cognitive institution' (or 'mental institution' [Gallagher and Crisafi, 2009]). This notion builds upon the externalist hypothesis called the 'socially extended mind' (Gallagher, 2013). The socially extended mind goes beyond Clark and Chalmers's limited examples of mind extendedness involving narrowly-intended cognitive artifacts and tools (such as pen and paper that would extend the mind while doing math, or pieces of technology that can help us solve problems as, e.g. navigating unfamiliar cities), and argues for counting instituted social practices and more generally social interactions as legitimate loci of cognitive extension.

This paper is structured as follows. Section 2 discusses the thread of institutional economics that connects Douglass North with Andy Clark. It considers Arthur Denzau and North's notion of 'shared mental models' and Clark's notion of 'scaffolding institution', emphasizing that they can be considered instances of increasing externalism in the foundations of institutional economics. Section 3 introduces the notion of 'cognitive institution' clarifying its basic features. In particular, this section shows that different types of extensive cognition can be categorized according to two main dimensions, functional integration and task dependency, and also gives a picture of the rich ontology of cognitive institutions. Finally, Section 4 shows that cognitive institutions can help address foundational issues in institutional economics. This section discusses the market as an economic cognitive institution.

\section{The externalist thread of institutional economics: shared mental models and scaffolding institutions}

\subsection{Denzau and North: shared mental models}

Looked at through the lens of the internalist/externalist distinction, Arthur Denzau and Douglass North's well-known definition of institution as 'shared mental models' (Denzau and North, 1994) is positioned between the two poles. On the one hand, mental models - roughly intended as

\footnotetext{
${ }^{1}$ Guala (2016) discusses 'meaning externalism' in the context of the philosophical foundation of institutions.
} 
representations of the external world located in agents' minds, no matter how accurate and reliable they are - belong to a markedly internalist position in philosophy of mind (e.g. Fodor, 1981). On the other hand, requiring that these mental models have to be 'shared' in order to constitute an institution possibly takes the first step toward an externalist understanding of institutions. It depends, however, on how the 'sharing' requirement is interpreted. The seeds of Denzau and North's externalism are less studied in the institutional economics literature but are also, in our view, the most promising starting point for further elaboration. The radical uncertainty typical of any preinstitutional phase is such that individuals' representations of their environment reflect their learning processes (Denzau and North, 1994: 3-4). In other words, mental models are shaped by the way in which individuals cope with the peculiarities of their environments. It is therefore reasonable, given this assumption, that individuals with common cultural backgrounds and experiences will share reasonably convergent mental models, ideologies, and institutions; and individuals with different learning experiences (both cultural and environmental) will have different theories (models, ideologies) to interpret their environment' (ibid.). In so far as individuals are collectively considered as a population that adapts to environments by developing convergent mental models, the transition from 'individual' to 'shared' mental models seems almost entirely determined by the external environment and by environmental pressure.

Once institutionalization is accomplished, shared mental models work in a twofold way: as ideologies or as institutions. Ideologies are more proximal to the 'mental' and 'internalist' dimension of shared mental models, as they consist of the 'shared framework of mental models that groups of individuals possess that provide both an interpretation of the environment and a prescription as to how that environment should be structured' (ibid.: 4). In other words, they are worldviews (in the sense of beliefs, judgments, prescriptions, etc.) shared by individuals who happen to have been exposed to similar environments. Institutions, on the other hand, are more distal from the mental dimension, as they are the ways in which ideologies are embodied. Following North's famous definition (North, 1990: 3-4), institutions are conceived as 'the rules of the game of a society and consist of formal and informal constraints constructed to order interpersonal relationships' (Denzau and North, 1994: 4). By using a central distinction in philosophy of mind, it can be said that ideologies are the 'content' while institutions are the 'vehicles' of what is shared (Clark, 2005). Denzau and North programmatically take the internal/external coordinates as a heuristic guide consistent with this interpretation:

The mental models are the internal representations that individual cognitive systems create to interpret the environment; the institutions are the external (to the mind) mechanisms individuals create to structure and order the environment (ibid.).

In a given institutional setting, individual mental representations persist and continue to play a relevant role each time individuals face uncertainty. This may happen, for instance, in the case of institutionally stable yet intrinsically uncertain situations, such as bilateral or multilateral bargain (ibid.: 10). In changing environments, in contrast, the process of mental model formation starts collectively once again (North, 2005). In general, mental models are needed more when the situation is particularly complex and the outcomes less foreseeable (Arthur, 1992). While in stable environments circumstantial complexity may trigger idiosyncratic mental models, unstable environments tend to trigger a process of collective mental model formation. North's scientific interest as an institutional theorist was less concerned with the microdynamics of individual decision processes than with the macro properties of an institutionalized state (see, e.g. North's correspondence in Hodgson, 2006). It is against this macro background that his definition of institutions as rules and constraints that order social life should be interpreted. In the next section, we will see that Clark's position, although very similar to North's in many regards, is more concerned with the microdynamic interaction between individuals and the institutional structure. 


\subsection{Clark: extended mind and scaffolding institution}

\subsubsection{The extended mind hypothesis}

Before discussing Clark's notion of 'scaffolding institution', it is propaedeutic to introduce the 'extended mind' hypothesis upon which it is established. This discussion will be also propaedeutic to introduce later the notion of 'socially extended mind' upon which 'cognitive institutions' are, in turn, established. As already mentioned, the extended mind hypothesis was originally introduced by Clark and Chalmers (1998), and is based on the so-called 'parity principle':

If, as we confront some task, a part of the world functions as a process which, were it done in the head, we would have no hesitation in recognizing as part of the cognitive process, then that part of the world is (so we claim) part of the cognitive process (Clark and Chalmers, 1998: 8).

To mention a well-known example, consider the task of doing math calculations. Individuals can do math either with the sole force of their internal cognitive faculties, in their heads, or with the help of pen and paper. The parity principle roughly states that in so far as pen and paper play the same functional role played by neurons in individuals' brains, that is, as vehicles of cognitive processes, they should be counted as part of an equivalent cognitive system. Another famous example introduced by Clark and Chalmers is that of Otto and Inga. Inga is a perfectly healthy person who uses her own memory to remember different sorts of information; Otto instead suffers from early-stage Alzheimer's disease, and like many patients in the same condition uses external devices, such as a notebook, to store and retrieve information that his internal memory is not able to store and process. The parity principle states that Otto's notebook is functionally equivalent to Inga's internal memory and, as such, Otto's (external) devices, as functional vehicles of cognitive processes, should be considered on the same footing as Inga's neurons.

The stated functional similarity between neurons and external devices has motivated various critiques. The most simple objection involves 'cognitive bloat' (Rupert, 2004) and concerns the inflationary attribution of the 'mental' status to too many things in the external world that we would not be intuitively comfortable in considering mental. Where should we draw a boundary between what counts as mind and what does not? What does characterize, in Adams and Aizawa's (2001) words, the 'mark of the mental'? Discussing Otto and Inga's example with the aim of identifying 'nonbiological candidates' that could count as memory extending, Clark (2008) addresses criticisms by identifying additional and more restrictive criteria for extendedness beyond functional equivalence:

(1) That the resource be reliably available and typically invoked. [...]

(2) That any information thus retrieved be more or less automatically endorsed. It should not usually be subject to critical scrutiny (e.g. unlike the opinions of other people). It should be deemed about as trustworthy as something retrieved clearly from biological memory.

(3) That information contained in the resource should be easily accessible as and when required. (p. 79)

Clark has further acknowledged (2008: 114) that the parity principle does not require a strict 'similarity' between internal and external processes. In some cases, what is in the head and what is in the world are distinctly different things. This has motivated a 'second wave' (Sutton, 2010) of research on the extended mind, characterized by a focus on 'cognitive integration' (Menary, 2007) rather than on 'functional similarity' between internal and external resources. In other words, 'the focus is not on whether or how much the internal and external resources have features in common, but on how they operate together in driving more-or-less intelligent thought and action' (Sutton et al., 2010: 525). More recently, there has been another step in the refinement of the extended mind hypothesis, leading to a 'third wave' of research under the label 'socially extended mind', which we will consider 
more in detail in Section $3 .^{2}$ In the next section, we consider Clark's idea of economic institutions as an application of the extended mind hypothesis and identify its roots in North's idea of institutions.

\subsubsection{Scaffolding institutions}

The collaboration between Douglass North and Andy Clark has been rather neglected in institutional economics. This may be because it never led to co-authorship. The manifest signs of this collaboration only consist of diffused cross-references and reciprocal manifestations of appreciation. In his most cognition-oriented book, for instance, North (2005: x) thanks Clark for the 'lengthy discussions [... that] improved my understanding of many crucial issues in cognitive science'. On his part, Clark abundantly cites North in his works on 'scaffolding institution' (Clark, 1997a, 1997b, Chapter 9). Luckily, texts alone are able to demonstrate a distinct line of continuity between the two.

Like Denzau and North, the starting point of Clark's account of institutions is individuals' cognitive adaptation to environmental circumstances. Among these circumstances, Clark notably mentions time pressure, which can be understood as the naturalistic counterpart of Denzau and North's 'uncertainty'. However, unlike Denzau and North, Clark does not immediately put mental models into the spotlight. Mental models remain, as we shall see, an important pillar of Clark's arguments but get diluted in less radical statements about their comprehensiveness. Adaptation, for instance, leads individuals to build only 'multiple partial models of the environment without attempting to integrate the information gathered into a consistent whole' (Clark, 1997a: 270). Mental models are also sometimes considered less central than decision heuristics in coping with time pressure (ibid.; see also Clark, 2001). Moreover, mental models do not seem to cause institutions, as is the case with Denzau and North's framework. ${ }^{3}$ The diminished emphasis and fewer requirements imposed on mental models make a noticeable difference with respect to North's notion of institution, in so far as this implies partially disintermediating the connection between individuals and external structures. Eventually, less dependence on mental models would help to resolve the internalist-externalist tension intrinsic to Denzau and North's model, concerning which Dequech (2006) points to some telling signs, and which Dequech (2013) tries to overcome by positing that what is shared in institutions are 'systems of rules of behavior or of thought' ( $p$. 85) rather than mental models. These remarks would suffice to rank Clark as more externalist than North.

Beyond this point of difference, Clark's arguments seem very much in line not only with those of Denzau and North (1994) but also with those of Satz and Ferejohn (1994). They all consider a question that Clark summarizes as follows:

why, given the gross psychological irrealism of its model of human choosing, has traditional [neoclassical] economics yielded at least moderately successful and predictive models of, for example, the behavior of firms (in competitive posted price markets) and of political parties, and of the outcomes of double action experiments'? Why also - on a less optimistic note - has it failed to illuminate a whole panoply of other economic and social phenomena? (Clark, 1997a: 271).

The answer to this question passes through the definition of two scenarios, the one called 'weakly constrained individual cogitation' and the other called 'highly scaffolded choice' (ibid.: 271). The weakly constrained case has much in common with highly uncertain situations - such as the bargaining case mentioned by Denzau and North - the outcome of which is unpredictable because there may be no rules, conventions, incentives, etc. - generally called 'external structures' - to constrain and drive them. In such cases, it is individual psychology that mostly determines behavior. In the case of highly scaffolded choice instead, 'external structures act as filters and constraints on the spaces of possible

\footnotetext{
${ }^{2}$ See Gallagher (2018a) for an updated account of research on the extended mind.

${ }^{3}$ As Clark says, 'firms and organizations provide an external resource in which individuals behave in ways dictated by norms, policies, and practices; norms, policies, and practices that may even become internalized as mental models' (Clark, 1997a: 279, emphasis added).
} 
real-time responses' (ibid.: 269). The idea unanimously shared by Denzau and North (1994), Satz and Ferejohn (1994), and Clark (1997a) is that 'neoclassical economics works (insofar as it works at all) only for the highly scaffolded cases' (p. 271). In the words of Satz and Ferejohn (quoted in Clark, 1997b: 182) that sounds like a paradox for economics: 'the theory of rational choice is most powerful in contexts where choice is limited'. To substantiate the weakly constrained/highly scaffolded distinction, Clark points to the asymmetry that he sees between market supply and market demand in competitive markets. As concerns the supply side, strong pressures in the competitive arena induce firms to maximizing behavior. ${ }^{4}$ This makes competitive markets cases of highly scaffolded choice for firms. 'By contrast, the theory of consumer behavior [the demand side] is weak and less successful. This is because individual worldviews and ideas loom large in consumer choice and the external scaffolding is commensurately weaker' (Clark, 1997a: 273). Subsequently in his analysis, Clark also acknowledges that scaffolding not only constrains but also 'expands our intellectual horizons'. In such cases, however, mental models and representations, mostly mediated through the artifact of language, regain a central role. Clark's idea, also used by Denzau and North, is that when environments change, mental representations undergo a process of 'representational redescription' (Clark and Karmiloff-Smith, 1993).

Stated as such, Clark's scaffolding institution does not sound particularly new to institutional economists. Becker (1962) was one of the first to acknowledge that neoclassical economics works because competitive pressure diminishes the role of individual psychological factors. In this line of argument, we also find Geoffrey Hodgson's conceptual distinction between 'agent-sensitive' and 'agent-insensitive' institutions where the former are institutionss 'in which the reigning equilibria or conventions can be significantly altered if the preferences or dispositions of some agents are changed, within a feasible set of personality types' (Hodgson, 2006: 16), while the latter are institutions in which the structure stands and scaffolds individuals' choices irrespective of individual psychologies. Furthermore, in the literature on organizations, the idea that organizational arrangements fix individual cogitations is ubiquitous. For instance, in a particularly explicit passage for our purposes, Kenneth Arrow argues that in organizations 'collective action can extend the domain of individual rationality' (Arrow, 1974: 16, quoted in Felin, 2015, emphasis added).

What comes as totally new in Clark's framework is the fact that he frames his notion of scaffolding institutions as an instance of the extended mind hypothesis. As he says, mentioning the famous example of pen and paper that extends the individual mind:

Institutions, firms, and organizations seem to me to share many of the key properties of pen, paper, and arithmetical practice (Clark, 1997a: 279).

This important passage, however, not only remains rather underdeveloped in Clark's study of scaffolding institution but, even more importantly, it seems to be rather in contrast with Clark's stricter requirements for cognitive extension (see Section 2.2.1). This is, in part, motivation for developing the notion of 'cognitive institution' as a way to programmatically go beyond Clark's restrictive interpretation of extended mind.

\section{Cognitive institutions}

\subsection{From the socially extended mind to cognitive institutions}

The notion of 'socially extended mind' represents, on some interpretations, a 'third wave' of studies on the extended mind (e.g. Cash 2013). As such, it is critical of Clark's original concept of extended mind in (at least) two regards. The first concerns Clark's three criteria for limiting mind extension as they seem

\footnotetext{
${ }^{4}$ For some ingenuities in Clark's economics, such as the idea that firms always act so as to maximize profits, see Gallagher et al. (2019).
} 
overly conservative. Once mind extension is accepted in principle, there seems no reason to think that working with less available, less automatically endorsed, and less accessible resources is any less extensive than working through pen and paper, or with a notebook or a calculator. For example, if reflective deliberation about one's strategy typically counts as a form of cognition, there seems no reason to hold that automatic endorsement that excludes critical scrutiny of information gained via extended resources (Clark's second criterion) is a requirement for extended cognition (for further discussion, see Gallagher and Crisafi, 2009: 46-47; Gallagher, 2013: 5-6). The second critical point raised against Clark's extended mind is that it retains a view of the mind mostly made of mental models and other forms of stored mental representations (beliefs, informational contents, propositional attitudes, etc.). The socially extended mind rather suggests looking at cognition in terms of activities and processes, such as problem-solving, decision-making, judgment, etc. Since possible resistance to the notion of socially extended mind from common sense ontology would with all likelihood stem from a failed appreciation of this point, we will reaffirm it in the course of our discussion when necessary.

These two critical points are useful for introducing the notion of 'cognitive' or 'mental' institution (Gallagher, 2011, 2013; Gallagher and Crisafi, 2009). As far as the first point is concerned, as we have already noticed, it seems that Clark violates his three restrictive criteria for mind extension when he states that '[i]nstitutions, firms, and organizations seem to me to share many of the key properties of pen, paper, and arithmetical practice' (Clark, 1997a: 279). Institutions, in this quote, are considered potentially extending the mind on the same footing as pen and paper; however, unlike pen and paper, they are not always available, automatically endorsed and accessible resources, at least not to the degree implied by Clark's criteria. The notion of cognitive institution is introduced to unambiguously pursue the idea that institutions are legitimate candidates for mind extension. This statement, however, would remain obscure if it were not associated with a radical re-conceptualization of what cognition is. As stated, the socially extended mind considers human cognition in terms of activities and processes, this being in evident contrast with North and Clark's approach. Even if Clark's account of institutions is less pervasively populated by mental models than North's (in the sense that Clark's mental models are partial, heuristic-like, non-causal, etc.), they are still intended as beliefs, representations, and propositional attitudes. What does the contrast between 'models' and 'processes' that we advocate entail for institutional theory? The idea is, in a nutshell, that institutions should not be understood as 'shared mental models' but rather as 'shared mental processes' (Gallagher, 2013: 7). As already mentioned, this is a crucial point in order to understand what cognitive institutions are, what they do, and what they actually extend, that is, what ontology they imply. ${ }^{5}$

The definition of cognitive institutions states that 'they are not only institutions with which we accomplish certain cognitive processes, but also are such that without them such cognitive processes would no longer exist' (Gallagher, 2013: 7). In philosophical terms, cognitive institutions would not only enable, but also constitute cognitive processes. Of course, in the same way in which not all external resources extend the mind in any situation (a pen used to stretch our reach to retrieve keys fallen in a manhole does not extend our mind), not all social interactions constitute an institution. But most of them involving social and cultural practices actually do. Crucially, what is required as a criterion of social extension is the coupling between agents and institutional resources. As Clark and Chalmers put it, to properly extend the mind, internal and external resources should integrate in a two-way interaction, creating a coupled system that can be seen as a cognitive system in its own right' (Clark and Chalmers, 1998: 8). In other words, it is the right kind of coupling that extends minds and constitutes the cognitive systems, to whatever degree of extension.

\footnotetext{
${ }^{5}$ The idea that the extended mind is a form of 'functionalist vehicle externalism' has put too much emphasis on the vehicles of cognition, as if pencil and paper or notebook were extensions of our brains (see Shapiro 2009: 268-269; and Gallagher 2013: 10). More properly the emphasis should be on the extension of cognitive processes made possible by those vehicles. In the case of cognitive institutions the emphasis is placed on the extension of cognitive processes.
} 
We can add some specification to the notion of coupling by distinguishing between (1) a simple causal relation where some one element $E$ is in a causal relation with $X$ if variations in $E$ produce variation in $X$ (De Jaegher et al., 2010 call $E$ a 'contextual factor'), (2) an enabling condition where some factor $C$ is an enabling condition if the absence of $C$ prevents $X$ from occurring, and (3) a constitutive relation which can be a part-whole relation, or in the case of dynamical processes, a reciprocal causal relation. ${ }^{6}$ Individuals and social interactions are said to enable an institution in so far as the institution would trivially not occur without individuals or interactions. At the same time, institutions enable cognitive processes in so far as cognitive processes would not occur - or would be performed less effectively - without dedicated institutions. In a stronger ontological sense, individuals and social interactions can be said to constitute an institution in so far as they are essential parts or processes in its operation and, likewise, institutions constitute cognitive processes in so far as those cognitive processes would not exist without such institutions.

A typical example provided by the literature on cognitive institutions is that of the legal system. Legal institutions are constituted in a mutual and dynamical pattern of interactive social processes and practices (constituting 'legal' cognitive processes) enacted by individual agents or groups or other institutions. ${ }^{7}$ The traditional definition considers the law as a set of rules, ${ }^{8}$ but this definition is rather diminutive of the actual way in which legal systems come into being and work in everyday life. In what follows, we will make some reference to legal institutions, but Section 4 will systematically refer to economic and market institutions.

\subsection{Two features of extendedness: functional integration and task dependency}

Philosopher Mark Slors has recently clarified some important conceptual issues behind the notion of socially extended cognition (Slors, 2019). He distinguishes a 'person-centered' approach that starts from the single individual and studies how institutions extend individual cognition (the approach of extended mind), from a 'system-based' approach that studies how cognitive systems emerge from the integration of individual cognitions (the approach of distributed cognition; see Hutchins, 2014). On the basis of this distinction, Slors advocates a reading of the socially extended mind in a way congruent with distributed cognition, since the system-based perspective would prevent it from incurring ontological critiques such as the 'cognitive bloat' objection (Rupert, 2004). Slors also provides a very useful distinction between 'functional integration' and 'task dependency'. Functional integration is defined as 'the extent to which the execution of tasks involves coupling with items external to the brain and body' (p. 1,189), so that high functional integration means that the coupling with external resources constitutes the cognitive process, while low functional integration signifies an enabling relation. For example, in the case of Otto and Inga, while Otto because of his illness is highly functionally integrated with his external memory supports, Inga is only lowly functionally integrated with them. Task dependency, on the other hand,

is the extent to which the intelligibility of a task depends on a larger whole of coordinated tasks. Task-dependency is a notion that is connected with coordination and planning. It is a normative notion in the sense that high task dependency means that tasks play specific roles in the overall organization of a cognitive system or a cultural cognitive ecosystem; roles that can be played properly or improperly (ibid.: 1190).

\footnotetext{
${ }^{6}$ The precise conception of constitutional relations in the context of extended mind and enactivist approaches to cognition is currently under debate (see Gallagher, $2018 \mathrm{~b}$ for a more detailed discussion).

${ }^{7}$ The word 'enact' is particularly important in this context, as the entire worldview expressed by the notions of socially extended mind and cognitive institution depends on the phenomenology-inspired thread in the philosophy of mind called 'enactivism' (Varela et al., 1991; Gallagher, 2017).

${ }^{8}$ 'The body of rules, whether proceeding from formal enactment or from custom, which a particular state or community recognizes as binding on its members or subjects' (Oxford English Dictionary).
} 
The legal system is a case characterized by high task dependency as the intelligibility of what a barrister does is inextricably linked not only to the codified body of laws and customs but also to what other figures, such as judges and clerks, do.

Slors suggests that functional integration and task dependency, variously combined along with their 'high' and 'low' dimensions, can help categorize different kinds of extensive cognition (Figure 1).

Embedded cognition is the case in which external resources enable individuals to perform cognitive activities (low functional integration) and individuals' activities are intelligible even without reference to the institutional background (low task dependency). Distributed cognition, on the opposite side of the spectrum, is a situation in which cognition is constituted by the right coupling between distributed components (agents and artifacts) of the system (high functional integration) and in which the action of one individual cannot be understood without referring to others' activities (high task dependency). Extended cognition (in Clark's sense) is considered a case of high functional integration in the sense that Otto has to be rightly coupled with his notebook in order to extend his mind, although writing and consulting a notebook are not processes the intelligibility of which is dependent on others' tasks. Finally, Slors introduces his new concept of 'symbiotic cognition' as a way to identify the notion of cognition that underpins cognitive institutions. Symbiotic cognition encompasses those cases in which one individual's cognitive processes acquire meaning only in the web of interrelationships with others' activities (high task dependency), without requiring a high degree of functional integration.

Every participant in a symbiotic system profits from whatever the system as a whole offers (e.g. education, justice, social coordination) while contributing only a small part. The tasks, jobs and roles of others in the system co-define and enable one's own task, but one does not have to perform them or even think about them, while nevertheless benefitting from the overall outcome of the system (ibid.: 1198).

We think that Slors' analysis is productive. We note, however, that conceiving of cognitive institutions as strictly symbiotic will be an oversimplification. As Slors indicates, 'both functional integration and task-dependency come in degrees' (p. 1,190). Accordingly, we think that more generally a cognitive institution always involves varying degrees of task dependency and functional integration. Slors may be generalizing too quickly from the example of the legal system which would be characterized, as he maintains, by high task dependency and low functional integration. But this is not necessarily the case with all cognitive institutions. The issue is more complex if not only cognitive institutions vary in degree between task dependency and functional integration, but also these different degrees depend on where one is looking in the system, or from what perspective one is looking at the system. The distinction between person-based and system-based perspectives, for example, is a distinction between different epistemological perspectives - different ways of viewing the same phenomenon which may serve different research agendas - but not definitive of particular institutional processes. From a system perspective, one sees high task dependency in the legal system, whereas from the perspective of the individual agent who engages with the system, one finds a significant degree of functional integration that helps to extend legal reasoning. A judge, for example, has to make the system work by engaging with contracts, law books, courtrooms, and other people. The specific tasks that constitute her legal reasoning are accomplished only through a functional engagement with instruments and people, which sometimes demands flexibility and creativity. All of the various elements in the legal system are instrumentally functional and at the same time form parts or processes of the legal structure that predefine the tasks carried out by individuals.

\subsection{The rich ontology of cognitive institutions}

The legal documents, courtroom practices, and legal figures the judge engages with are just an example of the rich population of elements constituting cognitive institutions. Cognitive institutions, we have argued, are enacted through the dynamic coupling between individuals and various external resources. 


\begin{tabular}{l|cc}
\multicolumn{1}{c}{$\begin{array}{c}\text { LOW FUNCTIONAL } \\
\text { INTEGRATION }\end{array}$} & $\begin{array}{c}\text { HIGH FUNCTIONAL } \\
\text { INTEGRATION }\end{array}$ \\
\hline LOW TASK DEPENDENCY & Embedded cognition & Extended cognition \\
HIGH TASK DEPENDENCY & Symbiotic cognition & Distributed cognition \\
& &
\end{tabular}

Figure 1. Different forms of extensive cognition (from Slors, 2019: 1191).

These resources, however, belong to different kinds, and to have a good grasp on what thinking and acting in a cognitive institution means, it is important to have an idea of these kinds.

The notion of cognitive artifact comes first in this taxonomy. Usually, cognitive artifacts are understood as 'physical objects made by humans for the purpose of aiding, enhancing, or improving cognition' (Hutchins, 1999: 126). Otto's notebook is a typical example of this. Hutchins (1999) makes clear that also natural objects may serve the purpose of aiding individuals' cognition, while Norman (1993) softens the requirement that cognitive artifacts have to be physical objects. In organizational and institutional theory, for instance, examples of non-strictly-physical cognitive artifacts are collective habits (Veblen, 1899; Dewey, 1922) and routines (Nelson and Winter, 1982). ${ }^{9}$ However, as argued by Malafouris (2013), nonphysical cognitive artifacts originate from some form of material engagement of individuals with their environment. Non-physical cognitive artifacts such as routines and habits place cognitive artifacts in a line of continuity with the notion of practice, which is also central to understanding cognitive institutions. Practice is a cornerstone of social theory, in so far as it has been proposed as a way to reconcile the agent/structure dichotomy (Bourdieu, 1977). Giddens (1984) emphasizes the centrality of practice and particularly of repeated practices - to obtain forms of social order. The literature on the extended mind has taken into consideration and debated the way practices, and particularly those emerging in specific cultures (cultural practices), may be legitimate loci of mind extension (in this regard Menary, 2013 refers to the notion of 'enculturated cognition'). In a more radical understanding, the socially extended mind has been found compatible with Latour's ontologically plural actor-network theory (see Kono, 2014). Although not the perspective advocated in this paper, this interpretation stems from an idea that we do advocate, namely, that what is constitutive, in ontological terms, of cognitive institutions are interactions, and particularly social interactions (De Jaegher et al., 2010; Gallagher, 2018b; in press 2020). Accordingly, in so far as cognitive artifacts originate in the processes of enculturation, object manipulation may be understood, in a very specific sense, as a proper form of (social) interaction. Furthermore, as social (intersubjective) interactions themselves constitute the unit of analysis in cognitive institutions, the analytical framework should accordingly shift from methodological individualism to what is called 'relational autonomy', that is, the view that the very definition of individuals is inextricably linked to the processes of mutual recognition in the social domain (Gallagher, 2017).

\section{Toward a notion of economic cognitive institution}

\subsection{Post-Northian institutional economics and the cognitive nature of institutions ${ }^{10}$}

At the beginning of this paper, we singled out a distinctively (and increasingly) externalist thread in institutional economics epitomized by the figures of North and Clark. This is a thread in which the notion of economic cognitive institution aims to be a natural step forward. Such a stylized representation of the externalist thread in institutional economics, however, might risk oversimplification. In

\footnotetext{
${ }^{9}$ This view of physical and non-physical cognitive artifacts is compatible with a niche-constructionist perspective on the extended mind (Sterenly, 2004).

${ }^{10} \mathrm{We}$ thank the reviewers for suggesting the need for this section and for the useful references.
} 
recent years, some works in new institutional economics (NIE) have advanced the externalist thread beyond North, and as such can represent valuable contributions to the characterization of economic cognitive institutions. For the lack of a better term, and for the various origins of these works within NIE, we will simply use the label 'post-Northian' institutional economics, although some scholars were coeval and even directly interacted with North.

NIE has been increasingly concerned with the distinctly cognitive role played by institutions. Hodgson (1988, Ch. 6) refers to a 'cognitive function' of institutions that Dequech (2006) would later re-name 'informational-cognitive function'. The cognitive function of institutions is informationbased to the extent institutions provide information about other agents by constraining their behaviors. As the informational-cognitive role has been extensively studied in economics, we are here particularly interested in two other cognitive functions performed by institutions, which have been called 'profound' and 'practical' (Dequech, 2013). Building upon Denzau and North's idea of shared mental models, the profound function of institutions helps agents to cognitively order reality, and integrates with the 'practical' function, that is, the role of institutions in cognitively solving (individual and social) problems by providing tacit knowledge and know-how. It is the far-reaching and indissoluble combination between the profound and the practical (and also the informational) cognitive functions that leads us to suggest that rather than playing some cognitive 'function(s)', institutions may have a genuinely cognitive 'nature'. Relevant in this ontological context is the work of Knight (1997), who also collaborated with North (see Knight and North, 1997), for he refers to the cognitive nature of institutions by adhering to Edwin Hutchins' view of distributed cognition (Hutchins, 1995; see Dequech, 2006). North's famous definition of institution as the rules of the game has been recently criticized for focusing too much on individual beliefs rather than on social beliefs (Greif and Mokyr, 2017). Although Denzau and North (1994), as we have tried to demonstrate in this paper, deal sufficiently with the social nature of beliefs in so far as they are required to be 'shared' in order to constitute an institution, we nonetheless agree with Greif and Mokyr's emphasis on the necessity of founding the study of institutions on 'social interactions' (Greif and Mokyr, 2017: 2, n. 1).

In the progressive approach toward a definition of economic cognitive institutions, the work of Aoki (2011) is also important. Although partially maintaining an internalist jargon populated by mental states and beliefs, Aoki founds his view of institutions as 'cognitive media' on the 'crucial role of social cognitive artifacts (public representations) that mediate between salient patterns of social interactions (the recursive states of play of societal games) and individual mental states (behavioral beliefs)' (Aoki, 2011: 22). In this framework, Aoki defines social-cultural artifacts as 'statutory laws, social norms, rule-based public and private organizations, contracts and so on in varied substances' (ibid.). This definition would severely restrict the notion of cognitive artifact that we have introduced in this paper if it altogether denied the material dimension of artifacts. Aoki seems to be aware of this when he juxtaposes a 'mentalist' to the 'materialist' view of institutions (p. 21). What is relevant from our perspective is that there would be in principle no harm - and arguably a series of conceptual and ontological benefits - in dovetailing the mentalist and the materialist view, and so considering cognitive artifacts in all their varieties and integration possibilities with individuals. Aoki's distinction between mentalist and materialist institutions is also important because it allows us to introduce a view of economic institutions that is the closest, not only in terms of contents but also in terms of references, to that of cognitive institution we introduce in this paper. Hegel's view of institutions, as reconstructed by Crisafi and Gallagher (2010), has been recently used by institutional economists to explain the nature of institutions as constitutive parts of economic cognitive processes (Boldyrev and Herrmann-Pillath, 2013; Herrmann-Pillath and Boldyrev, 2014). Pivotal constructs in economics, such as that of preference, have been reconstructed in their 'neither behavioral nor mental' status (Guala, 2019) by analogically using Hegel' idea of the passage from 'Subjective' to 'Objective' Spirit (e.g. Boldyrev and Herrmann-Pillath, 2013, Section 4).

In the next section, we will introduce the notion of economic cognitive institution, now supported by the philosophical analysis of different forms of extensive cognition (Section 3.2) and by externalist insights into institutional economics (Section 2 and this section). The notions of socially extended 
cognition and of cognitive institution are proposed as the sources of conceptual clarification. Our intention is not to simply superimpose the taxonomy of extensive forms of cognition onto the different externalist forms of economic institutions; indeed, it would be difficult to find perfect matches or to provide a precise mapping. Not only would it be difficult to categorize Denzau and North's view as being a clear-cut example of either extended, embedded, symbiotic, or distributed cognition, but it would even be difficult to categorize Clark's scaffolding institution as an example of extended cognition (as we have seen in Section 2, when Clark talks about institutions he violates his own restrictive criteria of mind extension [Clark, 2008]). The only reasonably good match would be Hayek's view of institutions (e.g. Hayek, 1945), which has often been understood as an example of distributed cognition (see Marsh, 2011), and particularly as an instance of the externalist notion of 'wide computationalism' (Wilson, 1994). Integrating the view of the socially extended mind with institutional economics, however, will allow us to liberally define economic institutions as entities that may embody different (but typically high) levels of task dependency and functional integration, also depending on whether we take a systemic versus individual agent perspective. Furthermore, we will see that the Hayekian distributed view of institutions may be an instance of cognitive institution only under certain conditions.

\subsection{Economic cognitive institutions}

At the first level of approximation, economic cognitive institutions can be understood as particular cases of cognitive institutions. The example of the legal system provided by the theorists of cognitive institutions is almost entirely analogous to the economic system. Undoubtedly, the economic system intended as the integrated system of economic institutions - contributes to the constitution of cognitive processes (forms of economic reasoning) that would not be available otherwise. In particular, these cognitive processes would not be possible (or meaningful) as the processes existing entirely in the heads of economic agents. The economic system is populated by roles and tasks that would not be possible or understandable outside of such an interconnected and interdependent system such as a market. That is, it involves a set of human interrelationships embedded in a workspace of different tasks and roles - government regulator or planner, corporation, manufacturing unit, information (or other service) provider, marketer, wholesaler, retail agent, purchaser, consumer (household), and any number of economic roles in between these categories. This renders economic systems distinctively task-dependent institutions: what one economic agent does depends to some degree, in terms of possibility and meaningfulness, on what other agents in the system do. Such interconnections make the forms of 'economic reasoning' what they are only in the specific systems in which they hold. At the same time, in terms of functional integration, as we have seen, the question depends on the form and degree of coupling that exists between the agent and the institution. While Slors rightly acknowledges that the two questions - how the individual can be extended by an institution and the role of the individual in making institutions - may serve different research purposes, from the ontological point of view they may be read as two faces of the same coin. In the case of economic cognitive institutions, this means that the way in which economic agents' reasoning processes are enabled or constituted by the economic system forms a complementary perspective to the way economic institutions are enacted through individuals' reasoning, actions, and interactions. This means, in philosophical terms, that the notion of constitution advocated by the socially extended mind approach is eminently dynamic (Gallagher, 2018b), and this applies also to the economic domain.

It may be useful to contrast this view with Searle's internalist view of institutions and to see that, like any other internalist view, it may not be sufficiently rich to account for the way in which economic institutions are constituted. Hindriks and Guala (2015) have recently suggested that Searle's constitutive-rule view of institutions is compatible with North's view in so far as it is 'shared' intentionality that constitutes social reality. Searle's notion of 'shared intentionality' is translatable into terms of 'shared mental models' to the extent that shared models are representations that remain entirely in the heads of individuals. The models are shared simply in the sense that one individual's representation is the same or similar in content to another individual's representation. As such, internalist models miss some entire 
classes of phenomena in economic institutions. For instance, cognitive artifacts and practices relevant to organizations and institutions, such as routines, are usually conceptualized as forms of 'external memory' (Nelson and Winter, 1982; Cohen and Bacdayan, 1994), and as such cannot be captured by purely internalist models - that is, models understood as internal representations.

Furthermore, internalist models miss another entire class of processes that are fundamental for constituting institutions: feedback and interactive processes. Think of the initial moment in which, on Searle's model, shared intentionality determines that some $X$ counts as $Y$ in $C$. In such a moment, a piece of paper $(X)$ may be given a conventional monetary value $(Y)$ able to determine causal effects in the social domain $(C)$. Now, what is missing in this account of the constitution of money is the other part of the story, that is, the way in which monetary objects and monetary institutions, in turn, change the original constituents themselves. Just to make a very simple example, it makes a big difference, in terms of cognition and behavior (e.g. risk-taking behavior), whether one is interacting with commodity money, paper money, electronic money, or cryptocurrencies. Differences in the patterns of what is called 'material engagement' (Malafouris, 2013) do change the causal effects that social objects have in the social domain, and have effects on the way people adapt or creatively re-functionalize social objects. In a nutshell, what any completely internalist account of institution misses is an entire line of causality that loops back from social objects and institutions (once institutionalized) to affect agents - it not just constrains or enables possibilities but also constitutes and even changes them. In still other words, what internalism lacks is a conceptualization of the dynamical, twoway coupling between individuals and institutions.

So far we have provided a definition of economic cognitive institutions that, borrowing a term used by Aoki (2011), we may call 'generic-ontological'. As such, we have defined cognitive institutions as extended cognitive processes in different domains (including the economic one), characterized by varying (but typically high) levels of task dependency and functional integration, and immersed in a rich world populated by epistemic artifacts, practices, and social interactions of a distinctly dynamic nature. This definition seems 'generic' in so far as it does not easily integrate with the extant knowledge and research interests of the economic discipline. In the latter context, we would require a definition of institution specific to institutional economics, a kind of definition that may be called 'specific-ontological'. North provides an interesting example of this generic/specific definition duality. His definition of institutions as shared mental models is a generic-ontological definition that provides the background to the specific-ontological definition of institution in the social sciences as the rules of the game. In this vein, we specifically define cognitive institutions in institutional economics as extended problem-solving entities. In so far as cognitive processes are understood pragmatically, that is, as ways to successfully act in the real world (Gallagher, 2017), cognitive institutions, as an extension of these pragmatic cognitive processes, can be defined as extended entities aimed to solve problems that individuals and society could not otherwise solve.

\subsection{The market as an economic cognitive institution}

In this section, we conceptualize the central institution in economics, the market, as a cognitive institution. To do so, it is useful once more to begin by considering North and Clark, as their notions of market provide interesting starting points for our arguments. As we have seen in Section 2, Denzau and North consider competitive markets as exemplary environments in which choices are 'simple', in the sense that they do not require much cognitive effort on the individuals' side: the market, they say, does most of the cognitive work. They consider the market as an offloading device for individuals' cognitive demands (see Risko and Gilbert, 2016). To support this view, Denzau and North mention the work by Gode and Sunder (1993) on 'zero-intelligence traders' which is particularly explicative of the off-loading process. Gode and Sunder demonstrate that even imposing minimalistic requirements on agents' rationality, strict market rules are able (almost alone) to account for high levels of market efficiency. Denzau and North point out that competitive markets guarantee this systemic outcome by having an effect on individual cogitations, and particularly by supporting agents' 
mental models. Competitive markets would not require individuals to have complex mental models, as would provide them with reliable and potentially immediate information, and foster motivation to transact by providing immediate feedback (p. 7). In this way, 'competitive markets provide a setting for easy choices' (ibid.). To this picture, Clark adds, as we mentioned, the idea that the market scaffolding does not work equally on all the sides of the market. He applies the distinction between 'highly scaffolded choice' and 'weakly constrained individual cogitation', respectively, to the supply and demand side of the market. On the supply side, competitive pressure would lead firms to align with the behavior of profit maximization (otherwise risking going out of business) in a context in which all the competitors feel the same evolutionarily-like pressure (Alchian, 1950). As Clark indicates, because of 'such powerful scaffolding, the particular theories and worldviews of individuals may at times make little impact on overall firm-level behavior' (1997a: 272). The situation would be rather different for the demand side of the market, where buyers are not constrained, at least not at the same level of pressure and urgency as sellers, by the rules of the market. Accordingly, Clark contends, individual biases in consumer behavior weaken the effects of external scaffolding as well as the predictive force of theory (for a critique see Gallagher et al., 2019).

Conceiving of markets as cognitive institutions involves less concern with the centrality of agents' mental models, as found in North and Clark, and more emphasis on market-related actions and interactive processes. Accordingly, to understand the market as a cognitive institution, it is crucial to conceptualize it in terms of judgment-related, decision-making activities performed in and by the market, which on the whole allow us to see the market as an extended problem-solving mechanism. As discussed in previous sections, from the agents' point of view, extension can go in the direction of enabling cognitive processes, providing a symbiotic background to agents' actions, or altogether constituting cognitive processes that would not exist without the market. Consider the simplest market actions available to market participants: bidding or asking a certain good at a certain price. This basic action can be understood as extending bidders and sellers' cognitive capacities in the specific cognitive and epistemic activity of value assessment. Individuals may perform value assessment by themselves, in their own heads so to say, on the basis of their subjective value. But the market also exists to make the process of value assessment more accurate in the sense of reflecting all available knowledge and information. Considered from the point of view of market actors, the price adjustment mechanism can be understood as an extension of their 'own' cognitive capacity to assess values, and market prices are, in turn, the outcome of this extended cognitive process. On this reading, the difference between subjective value and market prices is not entirely a difference of kind, as it is usually thought, but a difference in the extendedness of the epistemic process used to assess and determine values.

The distinction between 'pragmatic' and 'epistemic' action introduced by Kirsh and Maglio (1994) may help to characterize further the cognitive nature of market bidding and asking in our framework. Pragmatically, market operators bid or ask in order to get a step closer to their objective, which may be the closing of the transaction itself or, ultimately, consumption. However, from the epistemic point of view, the same action can be understood as a way to extend their own value assessment process. In other words, market operators bid and ask not only to close the transaction or consume the good but also to 'know more'. Pragmatic and epistemic reasons usually overlap and mingle but can be conceptually disentangled. As the outcome of the market operators' extended value assessment process, what from the point of view of the market is called 'efficiency', from the point of view of the agents is called accuracy and comprehensiveness of knowledge and information in their judgments about value. The case of the so-called prediction markets (Wolfers and Zitzewitz, 2004) is particularly relevant in this context, as they expunge the 'pragmatic' dimension (consumption) and show the epistemic dimension of markets in its purest form: there is no goods exchange in prediction markets, just the combination of epistemic actions to reach an effective prediction. This participatory, co-creational, and problem-solving view of the market mechanism is expressed by well-known models of the market (e.g. Arthur et al., 1996), although, in so far as they are typically built within internalist (e.g. beliefbased) frameworks, they differ from the models of cognitive institutions. The framework of cognitive institutions would suggest that more action-oriented concepts, such as 'social affordances', which are 
particularly relevant in market contexts (Felin et al., 2016), take the place of 'in-the-head' mentalist concepts such as beliefs. Social affordances, and market affordances in particular, are defined as action possibilities provided by the market, and as such are less cognitively demanding with respect to the full conceptualization of market opportunities (Ardichvili et al., 2003).

Once we lay aside the individual-centered perspective and assume the complementary system-based perspective, markets as cognitive institutions may be understood in terms of distributed cognition. As we have already noticed, Hayek's (1945) view of the market can be read as a specific case of distributed cognition called 'wide computationalism' (Wilson, 1994), in so far as individuals are conceived as interconnected nodes of a distributed computational network. Hayek's general view of institutions has been recently called 'epistemic institutionalism' (Boettke, 2018), a notion expressing the idea that different institutional arrangements affect the epistemic status of individuals who, in turn, affect the institutional outcome (such as, in the case of markets, market efficiency). Hayek's epistemic institutionalist side has been taken up and advanced by Vernon Smith (2007), whose view of institutions has been recently considered another example of distributed cognition (Dekker and Remic, 2018).

As distributed cognition may assume different shades of meaning, however, we suggest that Hayek's and other neo-Austrian views of the market may be compatible with the approach of the socially extended mind and of cognitive institution only under certain conditions. For the sake of clarity, we identify three of these conditions. The first can be read as an invitation to go back to the well-known example of the tin market that Hayek used as an illustration of the distributed adjustment mechanism of prices. While Hayek gave a stylized representation of the tin market (Hayek, 1945: 526), we invite the reader to think of the 'thickness' of the real-world counterpart. The very process of price adjustment, which starts from market operators who become aware of new use opportunities for tin and goes on with the complex machinery that operators activate to adjust to such novelty, is a thick, real-world process populated by the rich ontology of artifacts, routines, practices, and social interactions that characterize a particular market in a certain time and place (see, e.g. Callon, 1998; Callon and Muniesa, 2005; see also Mirowski, 2002). Real-world tin markets are populated by different sorts of artifacts for trading and sharing information, by laws which for instance regulate the allowed extent of speculation, or by different practices for closing contracts such as handshakes. The working, not to mention the effectiveness of the price mechanism, crucially depends on this ontologically rich infrastructure (e.g. MacKenzie, 2006). This is to say that although all tin markets of the world are distributed, distributedness per se risks becoming a one-size-fits-all notion that alone is not able to saliently represent real-world market mechanisms. There is a long and to a certain extent incommensurable line that goes from representing distributedness in terms of abstract computational mechanisms (Wilson, 1994) to that of conceiving of it in terms of culture-based cognitive artifacts (Hutchins, 2014). Distributedness can be compatible with our view of socially extended mind and cognitive institutions if it is ontologically rich and methodologically sophisticated. As an example of sophisticatedness, consider the neo-Austrian definition of knowledge as, among other things, 'exosomatic' and 'synecological', which makes it close to Hutchins' view of distributedness (Koppl, 2018). As a second requirement, market distributedness can be compatible with our view if understood as a bottom-up process, as Hayek and other Austrians understand it. Market interactions as conceived by Smith (2007), in contrast, are regulated within a pre-specified institutional setup, and this feature suffices to make it a top-down approach to markets rather incompatible with the view of cognitive institutions. Last but not least, the third requirement concerns relaxing the excessive focus on information found in distributed approaches to markets (Mirowski and Nil-Khah, 2017). The notion of cognitive institution emphasizes that what is distributed in the market is not only information but also artifacts, routines, practices, social interactions, and affordances that may all be called, synthetically but effectively, 'resources' for extended problem-solving processes.

\section{Concluding remarks}

Some theorists of economic institutions suggest that advancements in the conceptualization of economic institutions crucially depend on the close collaboration between economists and philosophers (see 
Hindriks and Guala, 2015; Guala, 2016). In this paper, we have tried to contribute to the conceptualization of economic institutions by relying on a specific strand of externalist philosophy of mind concerned with the 'socially extended mind' or 'socially extended cognition' (Gallagher, 2013). As such, this paper follows up on the suggestion that 'alternative conceptions of mind - including aggregate and plural ones - and institutional interfaces will help the field move forward and open up exciting possibilities for future research related to comparative organization (e.g. market and organizations), institutional forms and economic activity' (Felin, 2015: 523). The notion of 'economic cognitive institution' offers the opportunity to explore a set of possibilities for conceiving of economic institutions, that acknowledges differences in the individual and systemic points of view, and the varying degrees of functional integration and task dependency in institutional architecture, but with a strong insistence on a unitary ontological perspective founded on the notion of dynamical constitution.

Some final remarks should be devoted to the idea that notions such as the extended mind and the socially extended mind may be in conflict with common sense ontology. As a first response one could object, as Sugden (2015) does, that there is no necessity for institutional theory to be congruent with common sense ontology (even if this would certainly increase the acceptability of institutional theories by the general public). More importantly, however, we want to suggest that these concepts can help to provide an ontologically rigorous underpinning (and qualification) to ideas that are in daily use in the language of institutional economics; for example, the idea that '[s]tructural constraints, not individuals, do much of the explanatory work' (Hodgson, 2004: 438). These concepts may also help institutional theorists to find a way out of the 'deadlock' of reconciling minds and institutions (Rizzello and Turvani, 2000). This paper has advanced the idea that institutions do not just constrain or enable individual (economic) reasoning and behavior but are also constituted by the actions and interactions of individual agents. Once we acknowledge the centrality of social interactions and of the dynamical notion of constitution, institutions are no longer understood, as in Denzau and North and as in Clark, as structures that merely constrain and enable individual actions. Something more complex and richer goes on in institutions. Importantly, these reciprocally constituting relations where individuals in their social interactions enact institutions and institutions shape individuals and their social interactions can happen in either productive or unproductive ways. This gives us the opportunity to understand not only the origins of institutions, but also cases where they succeed or fail, crucially depending on whether individuals and institutions are rightly coupled or not. The ontological complexity behind the dynamical relationships involved in cognitive institutions motivates us to join the plea and ask for further collaboration between philosophers and economists in inquiring into the nature and workings of institutions.

Acknowledgements. We wish to thank Antonio Mastrogiorgio for useful discussions.

\section{References}

Adams, F. and K. Aizawa (2001), 'The Bounds of Cognition', Philosophical Psychology, 14(1): 43-64.

Alchian, A. A. (1950), 'Uncertainty, Evolution, and Economic Theory', Journal of Political Economy, 58(3): 211-221.

Aoki, M. (2011), 'Institutions as Cognitive Media Between Strategic Interactions and Individual Beliefs', Journal of Economic Behavior \& Organization, 79(1-2): 20-34.

Ardichvili, A., R. Cardozo, and S. Ray (2003), 'A Theory of Entrepreneurial Opportunity Identification and Development', Journal of Business Venturing, 18(1): 105-123.

Arrow, K. J. (1974), Limits of Organization, New York: W.W. Norton.

Arthur, W.B. (1992). On learning and adaptation in the economy, Santa Fe Institute Paper, n. 92 07-038.

Arthur, W. B., J. H. Holland, B. LeBaron, R. Palmer, and P. Tayler (1996), Asset Pricing Under Endogenous Expectations in an Artificial Stock Market. In W. B. Arthur, D. Lane and S. Durlauf (eds.), The Economy as an Evolving Complex System II, Reading, MA: Addison-Wesley, pp. 1-30.

Becker, G. S. (1962), 'Irrational Behavior and Economic Theory', Journal of Political Economy, 70(1): 1-13.

Boettke, P. J. (2018), FA Hayek: Economics, Political Economy and Social Philosophy, London: Palgrave Macmillan.

Boldyrev, I. A. and C. Herrmann-Pillath (2013), 'Hegel's “Objective Spirit”, Extended Mind, and the Institutional Nature of Economic Action', Mind \& Society, 12(2): 177-202. 
Bourdieu, P. (1977), Outline of a Theory of Practice, Cambridge, UK: Cambridge University Press.

Callon, M. (ed.) (1998), The Laws of the Markets. Oxford: Basil Blackwell.

Callon, M. and F. Muniesa (2005), 'Peripheral Vision: Economic Markets as Calculative Collective Devices', Organization Studies, 26(8): 1229-1250.

Cash, M. (2013), 'Cognition Without Borders: 'Third Wave' Socially Distributed Cognition and Relational Autonomy', Cognitive Systems Research, 25(1): 61-71.

Clark, A. (1997a), 'Economic Reason: The Interplay of Individual Learning and External Structure', in J. Drobak, and J. Nye (eds.), The Frontiers of the New Institutional Economics, San Diego, CA: Academic Press, pp. 269-290.

Clark, A. (1997b), Being There: Putting Brain, Body, and World Together Again, Cambridge, MA: MIT Press.

Clark, A. (2001), 'Reasons, Robots and the Extended Mind', Mind \& Language, 16(2): 121-145.

Clark, A. (2005), 'Intrinsic Content, Active Memory and the Extended Mind', Analysis, 65(1): 1-11.

Clark, A. (2008), Supersizing the Mind: Embodiment, Action, and Cognitive Extension, New York: Oxford University Press.

Clark, A. and D. Chalmers (1998), 'The Extended Mind', Analysis, 58(1): 7-19.

Clark, A. and A. Karmiloff-Smith (1993), 'The Cognizer's Innards: A Psychological and Philosophical Perspective on the Development of Thought', Mind \& Language, 8(4): 487-519.

Cohen, M. and P. Bacdayan (1994), 'Organizational Routines are Stored as Procedural Memory: Evidence from a Laboratory Study', Organization Science, 5(4): 554-568.

Crisafi, A. and S. Gallagher (2010), 'Hegel and the Extended Mind', AI \& Society, 25(1): 123-129.

De Jaegher, H., E. Di Paolo, and S. Gallagher (2010), 'Can Social Interaction Constitute Social Cognition?', Trends in Cognitive Sciences, 14(10): 441-447.

Dekker, E. and B. Remic (2018), 'Two Types of Ecological Rationality: Or How to Best Combine Psychology and Economics', Journal of Economic Methodology, 26(4): 1-16.

Denzau, A. T. and D. C. North (1994), 'Shared Mental Models: Ideologies and Institutions', Kyklos, 47(1): 3-31.

Dequech, D. (2006), 'The New Institutional Economics and the Theory of Behaviour Under Uncertainty', Journal of Economic Behavior and Organization, 59(1): 109-131.

Dequech, D. (2013), 'Economic Institutions: Explanations for Conformity and Room for Deviation', Journal of Institutional Economics, 9(1): 81-108.

Dewey, J. (1922), Human Nature and Conduct: An Introduction to Social Psychology, New York: Holt.

Felin, T. (2015), 'A Forum on Minds and Institutions', Journal of Institutional Economics, 11(3): 523-534.

Felin, T., S. Kauffman, A. Mastrogiorgio, and M. Mastrogiorgio (2016), 'Factor Markets, Actors, and Affordances', Industrial and Corporate Change, 25(1): 133-147.

Fodor, J. A. (1981), Representations: Philosophical Essays on the Foundations of Cognitive Science, Cambridge, MA: The MIT Press.

Gallagher, S. (2011), 'The Overextended Mind', Versus: Quaderni di Studi Semiotici, 112-113(1-2): 55-66.

Gallagher, S. (2013), 'The Socially Extended Mind', Cognitive Systems Research, 25(1): 4-12.

Gallagher, S. (2017), 'Social Interaction, Autonomy and Recognition', in L. Dolezal and D. Petherbridge (eds.), Body/Self/ Other: The Phenomenology of Social Encounters, London: Routledge, pp. 133-160.

Gallagher, S. (2018a), 'The Extended Mind: State of the Question', The Southern Journal of Philosophy, 56(4): 421-447.

Gallagher, S. (2018b), 'New Mechanisms and the Enactivist Concept of Constitution', in M. P. Guta (ed.), Consciousness and the Ontology of Properties, London: Routledge, pp. 207-220.

Gallagher, S. and A. Crisafi (2009), 'Mental Institutions', Topoi, 28(1): 45-51.

Gallagher, S., A. Mastrogiorgio, and E. Petracca (2019), 'Economic Reasoning and Interaction in Socially Extended Market Institutions', Frontiers in Psychology, 10: 1856.

Gallagher, S. (in press [April 2020]), Action and Interaction, Oxford: Oxford University Press.

Giddens, A. (1984), The Constitution of Society: Outline of the Theory of Structuration, Berkeley \& Los Angeles: University of California Press.

Gode, D. K. and S. Sunder (1993), 'Allocative Efficiency of Markets with Zero-Intelligence Traders: Market as a Partial Substitute for Individual Rationality', Journal of Political Economy, 101(1): 119-137.

Greif, A. and J. Mokyr (2017), 'Cognitive Rules, Institutions, and Economic Growth: Douglass North and Beyond', Journal of Institutional Economics, 13(1): 25-52.

Guala, F. (2016), Understanding Institutions: The Science and Philosophy of Living Together, Princeton, NJ: Princeton University Press.

Guala, F. (2019), 'Preferences: Neither Behavioural Nor Mental', Economics \& Philosophy, 35(3): 383-401.

Hayek, F. A. (1945), 'The Use of Knowledge in Society', The American Economic Review, 35(4): 519-530.

Herrmann-Pillath, C. and I. A. Boldyrev (2014), Hegel, Institutions and Economics: Performing the Social, London: Routledge.

Hindriks, F. and F. Guala (2015), 'Institutions, Rules, and Equilibria: A Unified Theory', Journal of Institutional Economics, 11(3): 459-480.

Hodgson, G. M. (1988), Economics and Institutions: A Manifesto for a Modern Institutional Economics, Philadelphia: University of Pennsylvania Press. 
Hodgson, G. M. (2004), The Evolution of Institutional Economics, London: Routledge.

Hodgson, G. M. (2006), 'What are Institutions?', Journal of Economic Issues, 40(1): 1-23.

Hutchins, E. (1995), Cognition in the Wild, Cambridge, MA: MIT Press.

Hutchins E. (1999), 'Cognitive artifacts', in R. A. Wilson and F. C. Keil (eds.), The MIT Encyclopedia of the Cognitive Sciences, Cambridge, MA: MIT Press, pp. 126-128.

Hutchins, E. (2014), 'The Cultural Ecosystem of Human Cognition', Philosophical Psychology, 27(1): 34-49.

Kirsh, D. and P. Maglio (1994), 'On Distinguishing Epistemic From Pragmatic Action', Cognitive Science, 18(4): 513-549.

Knight, J. (1997), 'Social Institutions and Human Cognition: Thinking About Old Questions in New Ways', Journal of Institutional and Theoretical Economics, 153(4): 693-699.

Knight, J. and D. C. North (1997), 'Explaining Economic Change: The Interplay Between Cognition and Institutions', Legal Theory, 3(3): 211-226.

Kono, T. (2014), 'Extended Mind and After: Socially Extended Mind and Actor-Network', Integrative Psychological and Behavioral Science, 48(1): 48-60.

Koppl, R. (2018), Expert Failure, New York: Cambridge University Press.

MacKenzie, D. (2006), An Engine, Not a Camera: How Financial Models Shape Markets, Cambridge, MA: MIT Press.

Malafouris, L. (2013), How Things Shape the Mind, Cambridge, MA: MIT Press.

Markey-Towler, B. (2016), 'I, Roboticus Oeconomicus: The Philosophy of Mind in Economics, and Why it Matters', Cambridge Journal of Economics, 41(1): 203-237.

Marsh, L. (ed.) (2011) Hayek in Mind: Hayek's Philosophical Psychology. Bingley, UK: Emerald.

Menary, R. (2007), Cognitive Integration: Mind and Cognition Unbounded, Basingstoke: Palgrave Macmillan.

Menary, R. (2013), 'Cognitive Integration, Enculturated Cognition and the Socially Extended Mind', Cognitive Systems Research, 25(1): 26-34.

Mirowski, P. (2002), Machine Dreams: Economics Becomes a Cyborg Science, New York: Cambridge University Press.

Mirowski, P. and E. Nik-Khah (2017), The Knowledge we have Lost in Information: The History of Information in Modern Economics, New York: Oxford University Press.

Nelson, R. R. and S. G. Winter (1982), An Evolutionary Theory of Economic Change, Cambridge, MA: Harvard University Press.

Norman, D. A. (1993), Things That Make Us Smart, Reading, MA: Addison Wesley.

North, D. C. (1990), Institutions, Institutional Performance and Economic Change, Cambridge, UK: Cambridge University Press.

North, D. C. (2005), Understanding the Process of Economic Change, Princeton, NJ: Princeton University Press.

Risko, E. F. and S. J. Gilbert (2016), 'Cognitive Offloading', Trends in Cognitive Sciences, 20(9): 676-688.

Rizzello, S. and M. Turvani (2000), 'Institutions Meet Mind: The Way Out of a Deadlock', Constitutional Political Economy, 11(2): 165-180.

Rupert, R. (2004), 'Challenges to the Hypothesis of Extended Cognition', The Journal of Philosophy, 101(8): 389-428.

Satz, D. and J. Ferejohn (1994), 'Rational Choice and Social Theory', The Journal of Philosophy, 91(2): 71-87.

Searle, J. R. (1995), The Construction of Social Reality, New York: The Free Press.

Searle, J. R. (2005), 'What is an Institution?', Journal of Institutional Economics, 1(1): 1-22.

Searle, J. R. (2010), Making the Social World: The Structure of Human Civilization, Oxford: Oxford University Press.

Shapiro, L. (2009), 'Review of Fred Adams and Ken Aizawa, "The Bounds of Cognition"', Phenomenology and the Cognitive Sciences, 8(2): 267-273.

Slors, M. (2019), 'Symbiotic Cognition as an Alternative for Socially Extended Cognition', Philosophical Psychology, 32(8): $1179-1203$

Smith, V. L. (2007), Rationality in Economics: Constructivist and Ecological Forms, New York: Cambridge University Press.

Sterelny, K. (2004), 'Externalism, Epistemic Artefacts and the Extended Mind', in R. Schantz (ed.), The Externalist Challenge, Berlin \& New York: de Gruyter, pp. 239-254.

Sugden, R. (2015), 'On "Common-Sense Ontology": A Comment on the Paper by Frank Hindriks and Francesco Guala', Journal of Institutional Economics, 11(3): 489-492.

Sutton, J. (2010), 'Exograms and Interdisciplinarity: History, the Extended Mind and the Civilizing process', in R. Menary (ed.), The Extended Mind, Cambridge, MA: MIT Press, pp. 33-81.

Sutton, J., C. Harris, P. Keil, and A. Barnier (2010), 'The Psychology of Memory, Extended Cognition and Socially Distributed Remembering', Phenomenology and the Cognitive Science, 9(4): 521-560.

Varela, F. J., E. Thompson, and E. Rosch (1991), The Embodied Mind: Cognitive Science and Human Experience, Cambridge, MA: MIT Press.

Veblen, T. B. (1899), The Theory of the Leisure Class: An Economic Study in the Evolution of Institutions, New York: Macmillan.

Wilson, R. A. (1994), 'Wide Computationalism', Mind, 103(411): 351-372.

Wolfers, J. and E. Zitzewitz (2004), 'Prediction Markets', Journal of Economic Perspectives, 18(2): 107-126. 


\section{Appendix 1: Glossary of philosophical terms}

\begin{tabular}{|c|c|}
\hline Cognitive artifact & $\begin{array}{l}\text { An artifact that supports and extends cognitive processes. It is not restricted to artificial } \\
\text { and material artifacts, but may include practices. }\end{array}$ \\
\hline Cognitive institution & $\begin{array}{l}\text { An institution that operates as a problem-solving entity when properly coupled with } \\
\text { cognitive agents (see 'Socially extended mind/cognition') }\end{array}$ \\
\hline Cognitive integration & $\begin{array}{l}\text { In contrast to the notion of functional equivalence, cognitive integration allows for } \\
\text { differential contributions from internal and external resources combined to perform a } \\
\text { certain cognitive function. }\end{array}$ \\
\hline $\begin{array}{l}\text { Constitutive relation/ } \\
\text { Dynamical } \\
\text { coupling }\end{array}$ & $\begin{array}{l}\text { The dynamical relationship of agents and external resources in a reciprocal-causal process } \\
\text { that constitutes a cognitive or social phenomenon. }\end{array}$ \\
\hline Distributed cognition & $\begin{array}{l}\text { Cognitive processes extended across multiple resources, including agents and material } \\
\text { instruments, and characterized by a high degree of functional integration and a high } \\
\text { degree of task dependency. }\end{array}$ \\
\hline Embedded cognition & $\begin{array}{l}\text { Cognition characterized by one-way causal constraints (e.g. from environments to agents), } \\
\text { low task dependency and low functional integration. }\end{array}$ \\
\hline $\begin{array}{l}\text { Enablement/ } \\
\text { Enabling } \\
\text { condition }\end{array}$ & $\begin{array}{l}\text { Relationship between agents and external resources in which the absence of the latter } \\
\text { prevents an underlying cognitive or social phenomenon from occurring. }\end{array}$ \\
\hline Enactivism/Enaction & $\begin{array}{l}\text { Phenomenologically-inspired thread in philosophy of mind that finds the origin of } \\
\text { cognitive phenomena in the interaction between embodied agents and their } \\
\text { environment. Enaction is the process through which a mental or cognitive phenomenon } \\
\text { comes into being through dynamical coupling between agent and environment. }\end{array}$ \\
\hline $\begin{array}{l}\text { Extended mind/ } \\
\text { cognition }\end{array}$ & $\begin{array}{l}\text { Hypothesis about the nature of cognition introduced by Clark and Chalmers (1998) } \\
\text { according to which cognitive processes do not necessarily take place in the head/brain } \\
\text { but can also be realized through external resources. It is characterized by a high degree } \\
\text { of functional integration and a low degree of task dependency. }\end{array}$ \\
\hline Externalism & $\begin{array}{l}\text { Philosophical position according to which cognitive phenomena are not confined to an } \\
\text { agent's internal (e.g. brain) processes, but also depend on environmental resources. }\end{array}$ \\
\hline $\begin{array}{l}\text { Functional } \\
\text { equivalence }\end{array}$ & $\begin{array}{l}\text { The similarity or parity between internal and external resources for cognitive functions } \\
\text { (e.g. memory). }\end{array}$ \\
\hline $\begin{array}{l}\text { Functional } \\
\text { integration }\end{array}$ & $\begin{array}{l}\text { The extent to which performing a task requires the agent's coupling with external } \\
\text { resources. }\end{array}$ \\
\hline Internalism & $\begin{array}{l}\text { Philosophical view according to which cognitive phenomena are confined to the agent's } \\
\text { internal (e.g. brain) processes. }\end{array}$ \\
\hline Relational autonomy & $\begin{array}{l}\text { The idea that an individual's autonomy depends on social relations and interactions. This } \\
\text { is a methodological principle alternative to methodological individualism. }\end{array}$ \\
\hline Social interactions & $\begin{array}{l}\text { Primarily, embodied interactions between agents; secondarily, social practices that involve } \\
\text { agents interacting with socially defined objects (e.g. money). }\end{array}$ \\
\hline $\begin{array}{l}\text { Socially extended } \\
\text { mind/cognition }\end{array}$ & $\begin{array}{l}\text { Cognitive processes enabled or constituted by practices involving social institutions and } \\
\text { characterized by varying degrees of functional integration and task dependency. }\end{array}$ \\
\hline Symbiotic cognition & $\begin{array}{l}\text { Form of cognition characterized by high task dependency and low functional integration } \\
\text { (Slors, 2019). }\end{array}$ \\
\hline Task dependency & $\begin{array}{l}\text { The extent to which the intelligibility of a task depends on a larger whole of coordinated } \\
\text { tasks (Slors, 2019). }\end{array}$ \\
\hline
\end{tabular}

Cite this article: Petracca E, Gallagher S (2020). Economic cognitive institutions. Journal of Institutional Economics 16, 747-765. https://doi.org/10.1017/S1744137420000144 